\title{
The effect of gastrointestinal patients' health literacy levels on gastrointestinal patients' health outcomes
}

\author{
Dae Hyun Kim ${ }^{1}$, Stephen J. O’Connor ${ }^{2}$, Jessica H. Williams ${ }^{2}$, William Opoku-Agyeman ${ }^{3}$, Daniel I. Chu ${ }^{4}$, \\ Seong Won Choi ${ }^{5}$
}

${ }^{1}$ Department of Health Care Administration, College of Business, Idaho State University, Pocatello, ID, USA; ${ }^{2}$ Department of Health Services Administration, School of Health Professions, University of Alabama at Birmingham, Birmingham, AL, USA; ${ }^{3}$ Department of Health Care Administration, School of Health and Applied Human Sciences, University of North Carolina Wilmington, Wilmington, NC, USA; ${ }^{4}$ Division of Gastrointestinal Surgery, School of Medicine, University of Alabama at Birmingham, Birmingham, AL, USA; ${ }^{5}$ Department of Health Care Administration, Trinity University, San Antonio, TX, USA

Contributions: (I) Conception and design: All authors; (II) Administrative support: DH Kim, SJ O'Connor; (III) Provision of study materials or patients: DH Kim, DI Chu; (IV) Collection and assembly of data: DH Kim, DI Chu; (V) Data analysis and interpretation: DH Kim, W OpokuAgyeman, SW Choi; (VI) Manuscript writing: All authors; (VII) Final approval of manuscript: All authors.

Correspondence to: Dae Hyun Kim. Idaho State University, 921 South $8^{\text {th }}$ Avenue, Pocatello 83209, ID, USA. Email: danielkim@isu.edu.

\begin{abstract}
Background: Health literacy has become a serious issue in the US healthcare system. At least half of American adults do not understand the complex medical communications used in the delivery of care, which leads to negative consequences on care quality, disparities, and costs. Furthermore, it can potentially have a negative effect on patients' health outcomes, since inadequate health literacy can make it difficult for patients to manage their medical issues. With digestive disorders being one of the most common ailments facing Americans, it is believed that examining health literacy levels of gastro-intestinal patients is crucial. Therefore, the aim of this study is to investigate the effect of gastrointestinal patients' health literacy levels on their health outcomes.
\end{abstract}

Methods: Two main data sources were used to collect the data. First, 589 gastrointestinal patients who received surgical care at a select university hospital took the BRIEF Health Literacy Screening Tool (BRIEF) survey to measure their health literacy levels. Second, patients' demographic information and medical outcomes were gathered through the Business Objects. Multivariate analyses were then conducted to examine the relationship between patients' health literacy levels on their health outcomes.

Results: The results of the study show that gastrointestinal patients' health literacy levels are negatively associated with their health outcomes (hospital length of stay, readmission, and complication).

Conclusions: Findings of the research indicate that patients' health outcomes can potentially be enhanced as more emphasis gets put on improving patients' health literacy levels.

Keywords: Health literacy; health outcomes; length of stay; readmission; complication

Received: 18 September 2020; Accepted: 22 January 2021; Published: 25 December 2021.

doi: $10.21037 /$ jhmhp-20-134

View this article at: http://dx.doi.org/10.21037/jhmhp-20-134

\section{Introduction}

Health literacy is defined as "the degree to which an individual bas the capacity to obtain, communicate, process, and understand basic health information and services needed to make appropriate decisions for the betterment of his or her health" (1). At least half of American adults may not understand the complex medical communications used in the delivery of care, leading to negative consequences on care quality, disparities, and costs (2). Inadequate health literacy levels have been associated with numerous health issues such as worse overall health (3), increased rate of obesity (4), and increased use of 
health services (3).

Inadequate health literacy is related to patients' inability to comport with a healthy lifestyle and subsequently results in patients having a higher body mass index (BMI) (4). By not being able to adhere to a positive lifestyle, patients will be more likely to engage in unhealthy eating habits, resulting in patients having a higher than average BMI. Higher BMI, which is a result of inadequate health literacy level, is one of the major factors that can increase the possibility of patients ultimately having to utilize health services. According to the National Institute of Heath and Friedland's modeling assumptions (5), it was estimated that the impact of inadequate health literacy cost the US healthcare system $\$ 1.6$ trillion to $\$ 3.6$ trillion (6), through negative health outcomes such as medical complication and readmissions. In other words, patients' inadequate health literacy levels can potentially have a negative impact on the US healthcare system.

Hence, many health literacy researchers have focused on how patients' health literacy levels can affect patients' health outcomes $(7,8)$. However, many of these papers focused on health literacy levels of patients experiencing one specific medical condition or surgical approach $(9,10)$. While a number of health literacy studies have focused attention on medical specialties such as oral care (11), acute care (12), and cardiovascular surgery (13), very few have examined gastrointestinal (GI) patients' health literacy levels. Studying health literacy levels of GI patients is important as digestive disorders are among the most common ailments facing Americans, and are estimated to account for over 100 million ambulatory care visits in the United States (14). Furthermore, being inadequately health literate can make it difficult for GI patients to manage their GI issues. While there are number of pre- and postsurgery complication prevention methods that providers can provide, it is ultimately up to the patients to follow the instructions that are given to them. In order for patients to follow these recommendations, they would need to be able to understand why they have to follow the instructions and what they need to do even after they get discharged to avoid readmissions or complications. Therefore, the aim of this study is to investigate the effect of GI patients' health literacy levels on their health outcomes.

We present the following article in accordance with the MDAR reporting checklist (available at http://dx.doi. org/10.21037/jhmhp-20-134).

\section{Methods}

\section{Study population}

A total of 589 patients who received surgical care from attending GI physicians at a select university hospital and took the BRIEF Health Literacy Screening Tool (BRIEF) survey from April of 2017 to August of 2019 were the sample for this study. The sample was collected as patients came in to the hospital to receive scheduled GI-related surgeries. Patients were asked if they would be willing to participate in the survey and once the agreement form was signed, the survey was administered before the patients underwent the surgery. Response rate came out to be $100 \%$ since the survey was included as triage in the hospital. Any patient that was seen in the hospital was registered and given the survey. Non-response bias was not suspected since the survey was integrated into normal series of questions, confirming patients' demographic information. Simple random sampling method was utilized for this study.

\section{Data collection}

A research team at the GI surgical department administered the BRIEF survey before undergoing their surgeries. The BRIEF survey (Table 1) is a 4-item questionnaire survey that captures patients' health literacy levels. Each question contains Likert scale responses that range from 1 to 5 , with 1 representing the lowest level of health literacy and 5 representing the highest level of health literacy (15). Question 4, however, is scaled from 1 (not at all) to 5 (extremely). The BRIEF survey is based on the sum of the four non-weighted items that can range from 4 to 20 (16). Scores that range from 4 to 12 indicate inadequate level of health literacy. Scores ranging from 13 to 16 indicate a marginal level of health literacy, and scores ranging from 17 to 20 reflect an adequate level of health literacy $(16,17)$.

There are number of reasons why the BRIEF survey was selected for this study. While survey tools, such as Test of Functional Health Literacy in Adults (TOFHLA) and Rapid Estimate of Adult Literacy Survey (REALMS), are readily used in other studies, some researchers have pointed out that these surveys are too narrowly focused on measuring patients' reading-related skills, instead of their ability to understand health-related materials $(15,18)$. Also, the number of questions and time it takes for patients to complete the survey are considerably higher for TOFHLA 
Table 1 Structure of BRIEF Health Literacy Screening Tool

Please circle the answer that best represents your response

1. How often do you have someone help you read hospital materials?
a. Always
b. Often
c. Sometimes
d. Occasionally
e. Never

2. How often do you have problems learning about your medical condition because of difficulty understanding written information?
a. Always
b. Often
c. Sometimes
d. Occasionally
e. Never

3. How often do you have a problem understanding what is told to you about your medical condition?
a. Always
b. Often
c. Sometimes
d. Occasionally
e. Never

4. How confident are you filling out medical forms by yourself?
a. Not at all
b. A little bit
c. Somewhat
d. Quite a bit
e. Extremely

and REALMS. With physicians and researchers realizing that many patients are not interested in taking surveys that are long and difficult to understand (15), BRIEF has been used more frequently in hospital and clinical settings $(19,20)$. The four-item BRIEF is a validated survey tool, which resulted in 0.77 Cronbach's alpha (15).

Besides the BRIEF survey, other sources of data were supplied by the GI surgical department's research team and Business Objects. The GI surgical department provided data on Current Procedural Terminology (CPT) codes, a measure of the specific types of surgical procedures associated with each patient. The Business Objects, an online platform that allows physicians and researchers access to patients' medical information with an IRB approval, provided data on patients' demographic information and medical outcomes such as gender, age, BMI, race, marital status, hospital length of stay, readmission status, complication status, insurance status, and physicians who conducted their surgeries.

\section{Statistical analysis}

Univariate analysis was employed to describe the underlying distribution of the study variables. Normality of variables was checked to ensure the correct statistical techniques were used to analyze the data. The Kruskal-Wallis $\mathrm{H}$ test was conducted to explore the bivariate relationship between GI patients' health literacy levels and length of stay in a hospital. Two separate chi-square tests were used to analyze the relationship between GI patients' health literacy levels and readmission status and complication status. Next, negative binomial regression analysis was conducted to analyze the relationship between patients' health literacy levels and their hospital length of stay. Two separate logistic regression models were then run to examine the relationship between patients' health literacy levels and their readmission and complication status. Analyses were conducted in Stata version 16 (Statacorp LLC, College Station, TX, USA).

\section{Ethical statement}

The study was conducted in accordance with the Declaration of Helsinki (as revised in 2013). The study was approved by the University of Alabama at Birmingham's office of IRB (IRB-300003397) and individual consent for this retrospective analysis was waived.

\section{Results}

\section{Descriptive analysis}

Table 2 presents the result of descriptive analyses. In total, there were 53 patients $(9.00 \%)$ who had inadequate health literacy levels, 64 patients $(10.87 \%)$ who had marginal health literacy levels, and 472 patients $(80.14 \%)$ who had adequate health literacy levels. There were 284 male 
Table 2 Result of descriptive analysis for independent and control variables

\begin{tabular}{|c|c|c|c|}
\hline \multirow{2}{*}{ Variables } & \multicolumn{3}{|c|}{ Patients' health literacy levels } \\
\hline & Inadequate & Marginal & Adequate \\
\hline $\begin{array}{l}\text { Number of patients, } \\
\mathrm{n}(\%)\end{array}$ & $53(9.00)$ & $64(10.87)$ & $472(80.14)$ \\
\hline \multicolumn{4}{|l|}{ Gender, n (\%) } \\
\hline Male & $30(5.09)$ & $34(5.77)$ & $220(37.35)$ \\
\hline Female & $23(3.90)$ & $30(5.09)$ & $252(42.78)$ \\
\hline Age, mean (SD) & $57.54(12.94)$ & $56.95(17.02)$ & $54.20(15.72)$ \\
\hline $\begin{array}{l}\text { Body mass index } \\
\left(\mathrm{kg} / \mathrm{m}^{2}\right) \text {, mean }(\mathrm{SD})\end{array}$ & $27.96(7.35)$ & $27.01(5.92)$ & $28.85(7.27)$ \\
\hline \multicolumn{4}{|l|}{ Marital status, n (\%) } \\
\hline Married & $21(3.57)$ & $27(4.58)$ & $259(43.97)$ \\
\hline Single & $20(3.40)$ & $21(3.57)$ & $140(23.77)$ \\
\hline Divorced & $7(1.19)$ & $6(1.02)$ & $44(7.47)$ \\
\hline Widowed & $5(0.85)$ & $10(1.70)$ & $29(4.92)$ \\
\hline \multicolumn{4}{|l|}{ Race* $^{*}$ n (\%) } \\
\hline White & $33(5.60)$ & $38(6.45)$ & $347(58.91)$ \\
\hline African American & $17(2.89)$ & $26(4.41)$ & $116(19.69)$ \\
\hline Hispanic & $2(0.34)$ & $0(0.00)$ & $6(1.02)$ \\
\hline American Indian & $1(0.17)$ & $0(0.00)$ & $3(0.51)$ \\
\hline \multicolumn{4}{|c|}{ Insurance status ${ }^{\star \star \star}, \mathrm{n}(\%)$} \\
\hline Public insurance & $38(6.45)$ & $40(6.79)$ & $128(21.73)$ \\
\hline Private insurance & $14(2.38)$ & $24(4.07)$ & 320 (54.33) \\
\hline Self-pay & $1(0.17)$ & $0(0.00)$ & $24(4.07)$ \\
\hline
\end{tabular}

GI physicians-number of patients treated, $n$ (\%)

\begin{tabular}{lccc} 
Physician 1 & $16(2.72)$ & $18(3.06)$ & $161(27.33)$ \\
Physician 2 & $13(2.21)$ & $19(3.23)$ & $117(19.86)$ \\
Physician 3 & $1(0.17)$ & $10(1.70)$ & $56(9.51)$ \\
Physician 4 & $10(1.70)$ & $5(0.85)$ & $58(9.85)$ \\
Physician 5 & $3(0.51)$ & $2(0.34)$ & $29(4.92)$ \\
Physician 6 & $3(0.51)$ & $2(0.34)$ & $14(2.38)$ \\
Physician 7 & $5(0.85)$ & $2(0.34)$ & $12(2.04)$ \\
Physician 8 & $1(0.17)$ & $3(0.51)$ & $11(1.87)$ \\
Physician 9 & $1(0.17)$ & $2(0.34)$ & $9(1.53)$ \\
Physician 10 & $0(0.00)$ & $1(0.17)$ & $5(0.85)$ \\
\hline
\end{tabular}

Table 2 (continued)
Table 2 (continued)

\begin{tabular}{|c|c|c|c|}
\hline \multirow{2}{*}{ Variables } & \multicolumn{3}{|c|}{ Patients' health literacy levels } \\
\hline & Inadequate & Marginal & Adequate \\
\hline \multicolumn{4}{|c|}{ Types of Gl surgeries, n (\%) } \\
\hline Low risk surgeries & $34(5.77)$ & $23(3.90)$ & $229(38.88)$ \\
\hline $\begin{array}{l}\text { Intermediate risk } \\
\text { surgeries }\end{array}$ & $9(1.53)$ & $21(3.57)$ & $118(20.03)$ \\
\hline High risk surgeries & $10(1.70)$ & $20(3.40)$ & $125(21.22)$ \\
\hline \multicolumn{4}{|c|}{ Length of stay in a hospital ${ }^{\star \star \star}$} \\
\hline Median (SD) & $3(5.92)$ & $3(4.05)$ & $1(4.58)$ \\
\hline Mean & 5.34 & 4.19 & 2.67 \\
\hline Variance & 35.38 & 16.38 & 20.99 \\
\hline \multicolumn{4}{|c|}{ Readmission status ${ }^{\star \star \star}, \mathrm{n}(\%)$} \\
\hline Yes & $27(4.58)$ & $19(3.23)$ & $9(1.53)$ \\
\hline No & $26(4.41)$ & $45(7.64)$ & $463(78.61)$ \\
\hline \multicolumn{4}{|c|}{ Complication status ${ }^{\star \star \star}, \mathrm{n}(\%)$} \\
\hline Yes & $33(5.60)$ & $38(6.45)$ & $23(3.90)$ \\
\hline No & $20(3.40)$ & $26(4.41)$ & $449(76.23)$ \\
\hline
\end{tabular}

patients and 305 female patients. The average age of patients that had inadequate health literacy levels was 57.54 [mean $=57.54$, standard deviation $(S D)=12.94$ ], while the average age of patients that had marginal health literacy levels was 56.95 ( mean $=56.95, \mathrm{SD}=17.02$ ), and the average age of patients that had adequate health literacy levels was 54.20 (mean $=54.20, \mathrm{SD}=15.72$ ). Furthermore, bi-variate analyses between GI patients' health literacy levels and control variables have indicated that proportions of health literacy levels are significantly different. More specifically, statistically significant differences were shown in race, insurance status, length of stay in a hospital, readmission status and complication status between three groups (inadequate $v s$. marginal $v s$. adequate health literacy levels).

\section{Multivariate analyses}

Table 3 presents results of multivariate analyses. In terms of GI patients' length of stay, significant relationship was shown with patients' health literacy levels. Three additional 
Table 3 Result of multivariate analyses, examination of the effect of GI patients' health literacy on their length of stay in a hospital, readmission status and complication status

\begin{tabular}{|c|c|c|c|}
\hline Variables & \multicolumn{3}{|c|}{ Multivariate analyses } \\
\hline Marginal & $0.91(0.15)$ & $0.41(0.19)$ & $1.29(0.59)$ \\
\hline \multicolumn{4}{|l|}{ Gender } \\
\hline Male & $0.84(0.07)^{\star}$ & $0.77(0.31)$ & $0.71(0.23)$ \\
\hline Female & Reference & Reference & Reference \\
\hline African American & $1.10(0.10)$ & $2.43(1.01)^{\star}$ & $1.56(0.56)$ \\
\hline Hispanic & $0.79(0.29)$ & $2.40(3.40)$ & $2.01(2.68)$ \\
\hline American Indian & $0.78(0.41)$ & $13.99(20.11)$ & $6.12(8.54)$ \\
\hline White & Reference & Reference & Reference \\
\hline \multicolumn{4}{|l|}{ Marital status } \\
\hline Single & $1.08(0.11)$ & $0.48(0.25)$ & $0.47(0.20)$ \\
\hline Divorced & $1.25(0.17)$ & $2.10(1.30)$ & $1.23(0.68)$ \\
\hline Physician 4 & $1.53(0.20)^{\star \star \star}$ & $2.77(1.74)$ & $3.15(1.67)^{\star}$ \\
\hline Physician 5 & $1.14(0.20)$ & $0.95(0.87)$ & $0.54(0.47)$ \\
\hline Physician 6 & $1.22(0.27)$ & $0.52(0.58)$ & $0.72(0.67)$ \\
\hline Physician 7 & $0.59(0.15)^{\star}$ & $2.46(2.18)$ & $11.33(8.68)^{\star \star}$ \\
\hline Physician 8 & $0.78(0.21)$ & $3.38(3.43)$ & $2.58(2.36)$ \\
\hline Physician 9 & $1.45(0.39)$ & $0.81(1.02)$ & $5.31(4.93)$ \\
\hline Physician 10 & $1.42(0.54)$ & $5.82(7.67)$ & $2.14(2.93)$ \\
\hline Physician 1 & Reference & Reference & Reference \\
\hline \multicolumn{4}{|l|}{ Insurance status } \\
\hline Private & $0.77(0.07)^{\star \star}$ & $0.26(0.11)^{\star \star}$ & $0.20(0.07)^{\star \star \star}$ \\
\hline
\end{tabular}

Table 3 (continued) 
Table 3 (continued)

\begin{tabular}{lccc}
\hline \multirow{2}{*}{\begin{tabular}{l} 
Variables \\
\cline { 2 - 4 }
\end{tabular}} & $\begin{array}{c}\text { Length of stay (negative binomial), } \\
\text { IRR (standard error) }\end{array}$ & $\begin{array}{c}\text { Readmission (logistic regression), } \\
\text { odds ratio (standard error) }\end{array}$ & $\begin{array}{c}\text { Complication (logistic regression), } \\
\text { odds ratio (standard error) }\end{array}$ \\
\hline Self-pay & $0.85(0.18)$ & $0.49(0.57)$ & $0.47(0.40)$ \\
Public & Reference & Reference & Reference \\
Types of surgery & & & $1.35(0.59)$ \\
Intermediate risk & $1.07(0.12)$ & $0.66(0.33)$ & $0.71(0.30)$ \\
High risk & $0.88(0.09)$ & Reference & Reference \\
Low risk & Reference & & $0.68)$ \\
\hline
\end{tabular}

*, $\mathrm{P}<0.05 ;{ }^{* \star}, \mathrm{P}<0.01$; ${ }^{\star \star \star}, \mathrm{P}<0.001$. Gl, gastrointestinal; BMI, body mass index.

factors resulted in having a significant relationship with GI patients' length of stay and those are: gender, physicians who operated on the patients, and insurance status. GI patients with adequate levels of health literacy, relative to GI patients with inadequate levels of health literacy, were expected to have a $37 \%$ lower incidence rate for length of stay in a hospital [incidence rate ratio (IRR) $=0.63,95 \%$ confidence interval (CI): 0.48, 0.83]. For patients' gender, male patients, compared to female patients, were expected to have a $26 \%$ lower incidence rate for length of stay in a hospital (IRR $=0.84,95 \%$ CI: $0.71,0.98)$. In terms of GI physicians who conducted the surgeries, patients that were operated on by physician 3, relative to patients that were operated on by physician 1, were expected to have a $27 \%$ lower incidence rate for length of stay in a hospital (IRR $=0.73,95 \%$ CI: $0.55,0.98)$. On the other hand, patients that were operated on by physician 4 , relative to patients that were operated on by physician 1 , were expected to have a $53 \%$ higher incidence rate for length of stay in a hospital (IRR $=1.53,95 \%$ CI: 1.18, 1.98). Furthermore, patients that were operated on by physician 7 , relative to patients that were operated on by physician 1 , were expected to have a $41 \%$ lower incidence rate for length of stay in the hospital (IRR $=0.59,95 \%$ CI: $0.36,0.98)$. Lastly, for patients' insurance status, patients who had private health insurance, compared to patients who had public health insurance, were expected to have a $23 \%$ lower incidence rate for length of stay in the hospital (IRR $=0.77,95 \%$ CI: 0.64, 0.93).

In terms of GI patients' readmission status, significant relationship was shown with patients' health literacy levels. Two additional factors resulted in having significant relationship with GI patients' readmission status and those are: race, and insurance status. The analysis indicated that GI patients with adequate health literacy levels had $98 \%$ lower odds of getting readmitted to the hospital, relative to patients with inadequate health literacy levels [odds ratio $(\mathrm{OR})=0.02,95 \% \mathrm{CI}: 0.01,0.06]$. On the other hand, African American GI patients had 143\% higher odds of getting readmitted to the hospital, relative to white patients $(\mathrm{OR}=2.43,95 \%$ CI: 1.08, 5.47). Lastly, patients with private health insurance had $74 \%$ lower odds of getting readmitted to the hospital, relative to patients with public health insurance (OR $=0.26,95 \% \mathrm{CI}: 0.11,0.61)$.

In terms of GI patients' complication status, significant relationship was shown with patients' health literacy levels. Two additional factors resulted in having significant relationships with GI patients' complication status and those were: GI physicians who operated on the patients, and health insurance status. The analysis indicated that GI patients with adequate health literacy levels had $96 \%$ lower odds of getting complications post-surgery, relative to patients with inadequate health literacy levels (OR $=0.04,95 \%$ CI: 0.02 , 0.09). On the other hand, patients that were operated on by physician 4 had $215 \%$ higher odds of getting complications post-surgery relative to patients that were operated on by physician 1 (OR $=3.15,95 \%$ CI: $1.11,8.93)$. Furthermore, patients that were operated on by physician 7 had 1013\% higher odds of getting complications post-surgery, relative to patients that were operated on by physician $1(\mathrm{OR}=11.33$, 95\% CI: 2.53, 50.82). Lastly, patients with private health insurance had $80 \%$ lower odds of getting complications postsurgery, relative to patients with public health insurance 
$(\mathrm{OR}=0.20,95 \%$ CI: 0.10, 0.40).

\section{Discussion}

The main research question for the study focused on examining the effect of GI patients' health literacy levels on GI patients' health outcomes. Three specific health outcomes were examined: GI patients' length of stay in a hospital, readmission status, and complication status. The result of negative binomial regression analysis indicated that there was a $37 \%$ decrease in the incidence rate of patients spending one extra day in the hospital for patients with adequate health literacy levels, compared to patients with inadequate health literacy levels (IRR $=0.63,95 \%$ CI: 0.48 , $0.83)$. Other studies examining the association between patients' health literacy levels and patients' length of stay in a hospital found similar results (21-23).

Results of logistic regression analysis indicated that GI patients with adequate health literacy levels had $98 \%$ decrease in the odds of being readmitted to the hospital, relative to patients with inadequate health literacy levels (OR $=0.02,95 \%$ CI: $0.01,0.06)$. The analysis also indicated that GI patients with adequate health literacy levels had $96 \%$ decrease in the odds of having post-surgery complications, relative to patients with inadequate health literacy levels $(\mathrm{OR}=0.04,95 \% \mathrm{CI}: 0.02,0.09)$. These results are similar to prior studies that have examined the associations between patients' health literacy levels and readmission/complication status. A study conducted by Cox et al. (24) showed that patients' low health literacy levels were associated with an increased rate of being readmitted to a hospital within 30 days after discharge. Similarly, a study conducted by Esen et al. (25) found that patients with low health literacy had an increased likelihood of having complications and that physicians should constantly educate patients about the importance of adequate dietary restrictions and constant exercise.

\section{Limitations}

This study has several limitations. First, results from this study might not be generalizable to diverse groups of patients because our study sample is specifically geared towards GI patients that underwent GI surgeries. Furthermore, participants who took the survey were all English speakers, which could be another reason why generalization of the study could be difficult. Next, this study included a small sample size in inadequate and marginal health literacy categories within the patients' health literacy variable. The results could have been affected by such a sample size discrepancy; however, this type of discrepancy is not uncommon in health literacy research $(17,19)$. Lastly, not all socioeconomic status (SES) variables were captured in the study. Although patient demographic variables were captured, SES variables such as educational level, monthly income, and employment status were not included in the analysis.

\section{Areas of future research}

With this study examining the effect of GI patients' health literacy levels on GI patients' health outcomes, there are several future research studies that can be conducted. Future studies should seek to create or observe the impact of health literacy interventions. This study found that patients' health literacy levels affect patients' health outcomes. A number of health literacy interventions exist, such as the teach-back method, eHealth intervention, and simplifying health information in educational materials $(26,27)$. Future research should be conducted to compare health literacy interventions to see which are most effective. In addition, new approaches to improving health literacy should be generated to assess their impact on patients' health outcomes.

Another approach to future studies could be to examine the effect of patients' health literacy levels on healthcare organizations' medical spending. The United States spends almost $20 \%$ of its gross domestic product (GDP) on healthcare, which accounts for about $\$ 3.5$ trillion in total and slightly over $\$ 10,000$ per person (28). Patients' health outcomes are important in terms of healthcare organizations' medical spending since lower readmission and complication rates can result in better financial outcomes for healthcare organizations. Researchers should build on results of this research to examine if adequate patients' health literacy levels can lower medical spending for healthcare organizations in the United States.

\section{Acknowledgments}

Funding: None.

\section{Footnote}

Reporting Checklist: The authors have completed the MDAR reporting checklist. Available at http://dx.doi.org/10.21037/ 
jhmhp-20-134

Data Sharing Statement: Available at http://dx.doi. org/10.21037/jhmhp-20-134

Conflicts of Interest: All authors have completed the ICMJE uniform disclosure form (available at http://dx.doi. org/10.21037/jhmhp-20-134). The authors have no conflicts of interest to declare.

Ethical Statement: The authors are accountable for all aspects of the work in ensuring that questions related to the accuracy or integrity of any part of the work are appropriately investigated and resolved. The study was conducted in accordance with the Declaration of Helsinki (as revised in 2013). The study was approved by the University of Alabama at Birmingham's office of IRB (IRB-300003397) and individual consent for this retrospective analysis was waived.

Open Access Statement: This is an Open Access article distributed in accordance with the Creative Commons Attribution-NonCommercial-NoDerivs 4.0 International License (CC BY-NC-ND 4.0), which permits the noncommercial replication and distribution of the article with the strict proviso that no changes or edits are made and the original work is properly cited (including links to both the formal publication through the relevant DOI and the license). See: https://creativecommons.org/licenses/by-nc-nd/4.0/.

\section{References}

1. Berkman ND, Davis TC, McCormack L. Health Literacy: What Is It? J Health Commun 2010;15:9-19.

2. Institute of Medicine. Health Literacy: A Prescription to End Confusion. Washington, DC: The National Academies Press, 2004.

3. Kalichman SC, Rompa D. Functional Health Literacy is Associated with Health Status and Health-Related Knowledge in People Living with HIV-AIDS. J Acquir Immune Defic Syndr 2000;25:337-44.

4. James DC, Harville C, Efunbumi O, et al. Health literacy issues surrounding weight management among African American women: a mixed methods study. J Hum Nutr Diet 2015;28 Suppl 2:41-9.

5. Friedland R. New estimates of the high costs of inadequate health literacy. Proceedings of Pfizer Conference "Promoting Health Literacy: A Call to Action",
Washington, DC; 1998.

6. Vernon JA, Trujillo A, Rosenbaum S, et al. Low health literacy: implications for national health policy. Storrs, CT: University of Connecticut, 2007.

7. Lincoln A, Paasche-Orlow MK, Cheng DM, et al. Impact of Health Literacy on Depressive Symptoms on Mental Health-Related: Quality of Life Among Adults with Addiction. J Gen Intern Med 2006;21:818-22.

8. Peterson PN, Shetterly SM, Clarke CL, et al. Health Literacy and Outcomes Among Patients with Heart Failure. JAMA 2011;305:1695-701.

9. Kripalani S, Gatti, ME, Jacobson TA. Association of Age, Health Literacy and Medication Management Strategies with Cardiovascular Medication Adherence. Patient Educ Couns 2010;81:177-81.

10. Park NH, Song MS, Shin SY, et al. The Effects of Medication Adherence and Health Literacy on Health-Related Quality of Life in Older People with Hypertension. Int J Older People Nurs 2018;13:e12196.

11. Berkman ND, Sheridan SL, Donahue KE, et al. Low health literacy and health outcomes: an updated systematic review. Ann Intern Med 2011;155:97-107.

12. Davis TC, Arnold C, Berkel HJ, et al. Knowledge and attitude on screening mammography among low-literate, low-income women. Cancer 1996;78:1912-20.

13. Conlin KK, Schumann L. Literacy in the Health Care System: A study on Open Heart Surgery Patients. J Am Acad Nurse Pract 2002;14:38-42.

14. Almario CV, Ballal ML, Chey WD, et al. Burden of Gastrointestinal Symptoms in the United States: Results of a Nationally Representative Survey of Over 71,000 Americans. Am J Gastroenterol 2018;113:1701-10.

15. Haun J, Luther S, Dodd V, et al. Measurement Variation Across Health Literacy Assessments: Implications for Assessment Selection in Research and Practice. J Health Commun 2012;17:141-59.

16. Chew LD, Bradley KA, Boyko EJ. Brief questions to identify patients with inadequate health literacy. Fam Med 2004;36:588-94.

17. Wallace LS, Rogers ES, Roskos SE, et al. Brief Report: Screening Items to Identify Patients with Limited Health Literacy Skills. J Gen Intern Med 2006;21:874-7.

18. Baker DW, Parker RM, Williams MV, et al. The Relationship of Patient Reading Ability to Self-Reported Health and Use of Health Services. Am J Public Health 1997;87:1027-30.

19. Wallston KA, Cawthon C, McNaughton CD, et al. Psychometric Properties of the Brief Health Literacy 
Screen in Clinical Practice. J Gen Intern Med 2014;29:119-26.

20. Sand-Jecklin K, Coyle S. Efficiently Assessing Patient Health Literacy: the BHLS instrument. Clin Nurs Res 2014;23:581-600.

21. Jaffee EG, Arora VM, Matthiesen MI, et al. Health Literacy and Hospital Length of Stay: An Inpatient Cohort Study, J Hosp Med 2017;12:969-73.

22. Rao PR. Health Literacy: The Cornerstone of Patient Safety. The ASHA Leader 2007;12:8-21.

23. Cho YI, Lee SY, Arozullah AM, et al. Effects of Health Literacy on Health Status and Health Service Utilization Among the Elderly. Soc Sci Med 2008;66:1809-16.

24. Cox SR, Liebl MG, McComb MN, et al. Association between health literacy and 30-day healthcare use after

doi: 10.21037/jhmhp-20-134

Cite this article as: Kim DH, O'Connor SJ, Williams JH, Opoku-Agyeman W, Chu DI, Choi SW. The effect of gastrointestinal patients' health literacy levels on gastrointestinal patients' health outcomes. J Hosp Manag Health Policy 2021;5:34. hospital discharge in the heart failure population. Res Social Adm Pharm 2017;13:754-8.

25. Esen I, Demirci H, Güçlü M, et al. The Relationship between Health Literacy, Diabetic Control, and DiseaseSpecific Complications in Patients with Type 1 Diabetes Mellitus. South Clin Ist Euras 2018;29:151-6.

26. Yen PH, Leasure AR. Use and Effectiveness of the TeachBack Method in Patient Education and Health Outcomes. Fed Pract 2019;36:284-9.

27. Jacobs RJ, Lou JQ, Ownby RL, et al. A Systematic Review of eHealth interventions to improve health literacy. Health Informatics J 2016;22:81-98.

28. Branning G, Vater M. Healthcare Spending: Plenty of Blame to Go Around. Am Health Drug Benefits 2016;9:445-7. 